\title{
Gastric cancer, nutritional status, and outcome
}

\section{Xuechao Liu ${ }^{1,2, *}$ \\ Haibo Qiu ${ }^{1,2, *}$ \\ Pengfei Kong ${ }^{1,2, *}$ \\ Zhiwei Zhou ${ }^{1,2}$ \\ Xiaowei Sun ${ }^{1,2}$}

'State Key Laboratory of Oncology in South China, Collaborative Innovation Center for Cancer Medicine, ${ }^{2}$ Department of Gastric Surgery, Sun Yat-sen University Cancer Center, Guangzhou, People's Republic of China

*These authors contributed equally to this work
Correspondence: Xiaowei Sun Department of Gastric Surgery, Sun Yat-sen University Cancer Center, 65I East Dongfeng Road, Guangzhou 510060, Guangdong Province, People's Republic of China Fax +86208734 3I 23 Email sunxw@sysucc.org.cn
This article was published in the following Dove Press journal:

OncoTargets and Therapy

12 April 2017

Number of times this article has been viewed

Background: We aim to investigate the prognostic value of several nutrition-based indices, including the prognostic nutritional index (PNI), performance status, body mass index, serum albumin, and preoperative body weight loss in patients with gastric cancer (GC).

Materials and methods: We retrospectively analyzed the records of 1,330 consecutive patients with GC undergoing curative surgery between October 2000 and September 2012. The relationship between nutrition-based indices and overall survival (OS) was examined using Kaplan-Meier analysis and Cox regression model.

Results: Following multivariate analysis, the PNI and preoperative body weight loss were the only nutritional-based indices independently associated with OS (hazard ratio [HR]: 1.356, 95\% confidence interval [CI]: 1.051-1.748, $P=0.019$; HR: 1.152 , 95\% CI: $1.014-1.310, P=0.030$, retrospectively). In stage-stratified analysis, multivariate analysis revealed that preoperative body weight loss was identified as an independent prognostic factor only in patients with stage III GC (HR: 1.223 , 95\% CI: 1.065-1.405, $P=0.004$ ), while the prognostic significance of PNI was not significant (all $P>0.05$ ). In patients with stage III GC, preoperative body weight loss stratified 5 -year OS from $41.1 \%$ to $26.5 \%$. When stratified by adjuvant chemotherapy, the prognostic significance of preoperative body weight loss was maintained in patients treated with surgery plus adjuvant chemotherapy and in patients treated with surgery alone $(P<0.001 ; P=0.003)$.

Conclusion: Preoperative body weight loss is an independent prognostic factor for OS in patients with GC, especially in stage III disease. Preoperative body weight loss appears to be a superior predictor of outcome compared with other established nutrition-based indices.

Keywords: nutritional status, preoperative body weight loss, prognosis, gastric cancer, adjuvant chemotherapy

\section{Introduction}

Gastric cancer (GC) is the second most common cause of cancer-related deaths worldwide, with a high incidence of recurrence and metastasis. ${ }^{1-3}$ The postoperative survival of patients with GC remains unsatisfactory despite great improvements in surgical procedures and multidisciplinary treatment. ${ }^{4,5}$ Prevention and individualized treatment are considered the best choices to reduce GC mortality rates. ${ }^{6}$ Therefore, efforts to identify prognostic factors that select high-risk patients for targeted, individualized therapy have increased.

Nutritional status has been closely linked to cancer mortality. ${ }^{7,8}$ Recently, studies have proved that several nutrition-based indices, such as the prognostic nutritional index (PNI), body mass index (BMI), serum albumin, and preoperative body weight loss, have important prognostic value across varied malignancies, including GC. ${ }^{9-12}$ A study of 1,249 cases from Chen et al found that a low BMI might be associated with poorer survival among patients with stage III-IV GC. ${ }^{13}$ Hinata et al reported that impaired performance status was associated with an unfavorable prognosis in patients with urothelial carcinoma of the bladder who underwent radical cystectomy. ${ }^{14}$ 
One recent study revealed that preoperative PNI values maybe a useful predictor of long-term survival in patients with stage I and II GC. ${ }^{15}$ However, another study showed that PNI was a useful marker for predicting the long-term outcomes in patients with stage I and III GC. ${ }^{16}$ Therefore, the relationship between the nutrition-based indices and GC prognosis remains inconclusive.

In this large-scale retrospective study, we investigated the prognostic value of several nutrition-based indices in patients undergoing curative resection for GC.

\section{Materials and methods}

\section{Study population}

We retrospectively analyzed clinicopathological data from 1,330 consecutive GC patients who received surgical resection at Sun Yat-sen University Cancer Center between October 2000 and December 2012. Experienced surgeons performed D2 gastrectomy with R0 resection following the Japanese Research Society for Gastric Cancer guidelines. ${ }^{17}$ All patients had histologically confirmed stage I-III gastric adenocarcinoma. Our study complied with the standards of the Declaration of Helsinki, and the Ethics Committee of Sun Yat-sen University Cancer Center approved the study. All patients provided written informed consent.

Patients who met all the following eligibility criteria were included in the study: 1) the medical record contained all clinicopathological data and follow-up data, 2) no neoadjuvant chemotherapy or radiotherapy, 3) no other synchronous malignancy, and 4) no preoperative intravenous nutrition (eg, albumin) 1 month prior to surgery.

The patients' clinicopathological data were retrieved from our hospital information system. The blood sample was collected within 2 weeks prior to surgery. Unintentional preoperative body weight loss in the previous 6 months was recorded at the time of diagnosis. The time from diagnosis to surgery was $\sim 7$ days for most of the patients in our study. Tumors were staged using the seventh edition of the American Joint Committee on Cancer tumornode-metastasis (TNM) classification. ${ }^{18}$ According to current guidelines, patients with high-risk stage II or III GC and no marked comorbidities precluding chemotherapy use were offered primarily 5-fluorouracil-based adjuvant chemotherapy after surgery. ${ }^{19}$

\section{Follow-up}

All patients were routinely examined every 6 months during the first 2 years after surgery and every year thereafter. Postoperative follow-up assessment included laboratory testing, gastroscopy, and dynamic CT. The final follow-up date was June 25, 2015. Overall survival (OS) was defined as the time from the date of surgery until death or the last available follow-up.

\section{Nutrition-based indices}

Based on the standard Eastern Cooperative Oncology Group response criteria, performance status was recorded prior to surgery. Serum albumin was analyzed using standard threshold.

The PNI was calculated as follows: patients with a combined albumin $(\mathrm{g} / \mathrm{L}) \times$ total lymphocyte count $\times 10^{9} / \mathrm{L}$ of $\geq 45$ were assigned a score of 0 . Patients with this total score $<45$ were assigned a score of $1 .^{20}$

The preoperative body weight loss was defined as "no, or limited" ( $\leq 10 \%)$ or "severe" $(>10 \%)$, and the BMI was categorized as previously described $\left(<18.5 \mathrm{~kg} / \mathrm{m}^{2}, \geq 18.5\right.$ to $\left.<25.0 \mathrm{~kg} / \mathrm{m}^{2}, \geq 25.0 \mathrm{~kg} / \mathrm{m}^{2}\right) .{ }^{11,13}$

\section{Statistical analysis}

Comparisons between groups were performed using the Pearson chi-square test and the Kruskal-Wallis test. Survival curves were calculated using the Kaplan-Meier method and were generated from univariate data. The log-rank test was used to determine differences in survival rates between the curves. All significant variables $(P<0.05)$ in the univariate analysis were entered into a multivariate Cox proportional hazard model. All variables were assessed for interaction and collinearity. Statistical analyses were performed using the IBM SPSS 19.0 software (IBM Corporation, Armonk, NY, USA). Two-sided $P$-values $<0.05$ were considered significant.

\section{Results}

Of the 1,330 enrolled patients, the median age at the time of diagnosis was 59 years (range 19-89 years). Of all patients, $905(68 \%)$ were males and $425(32 \%)$ were females. A total of 220 patients had stage I disease, 334 had stage II, and 776 had stage III (Table 1). The median follow-up period was 35 months (range 1-179). During the follow-up period, 524 (39.4\%) patients died. A total of 806 (60.6\%) patients were alive at the last follow-up. None of the patients died within the first 30 days after surgery.

Our univariate analysis showed that, of all measures of nutrition-based indices, PNI, serum albumin, and preoperative body weight loss were associated with OS (Table 2). However, on multivariate analysis, only PNI (hazard ratio [HR]: 1.356, 95\% confidence interval [CI]: 1.051-1.748, 
Table I General characteristics of I,330 gastric cancer patients

\begin{tabular}{|c|c|}
\hline Characteristics & No of patients (\%) \\
\hline \multicolumn{2}{|l|}{ Age (years) } \\
\hline$<60$ & $704(52.9)$ \\
\hline$\geq 60$ & $626(47.1)$ \\
\hline \multicolumn{2}{|l|}{ Sex } \\
\hline Male & $905(68.0)$ \\
\hline Female & $425(32.0)$ \\
\hline \multicolumn{2}{|l|}{ Tumor size $(\mathrm{cm})$} \\
\hline$<5$ & $738(55.5)$ \\
\hline$\geq 5$ & $592(44.5)$ \\
\hline Tumor location upper third & $511(38.4)$ \\
\hline Middle third & $278(20.9)$ \\
\hline Lower third & $54 I(40.7)$ \\
\hline \multicolumn{2}{|l|}{ Histological grade } \\
\hline Well differentiated & $225(16.9)$ \\
\hline Poorly differentiated & $\mathrm{I}, 105(83.1)$ \\
\hline \multicolumn{2}{|l|}{ Prognostic nutritional index } \\
\hline 0 & I, I 87 (89.2) \\
\hline 1 & $143(10.8)$ \\
\hline \multicolumn{2}{|l|}{ Performance status } \\
\hline 0 & $364(27.4)$ \\
\hline I & $910(68.4)$ \\
\hline 2 & $56(4.2)$ \\
\hline \multicolumn{2}{|l|}{ Body mass index $\left(\mathrm{kg} / \mathrm{m}^{2}\right)$} \\
\hline$<18.5$ & $550(4 I .4)$ \\
\hline$\geq 18.5$ to $<25.0$ & $443(33.3)$ \\
\hline$\geq 25.0$ & $337(25.3)$ \\
\hline \multicolumn{2}{|l|}{ Serum albumin $(g / L)$} \\
\hline$\geq 35$ & I,207 (90.8) \\
\hline$<35$ & $123(9.2)$ \\
\hline \multicolumn{2}{|l|}{ Preoperative body weight loss } \\
\hline No & $684(5 \mathrm{I} .4)$ \\
\hline Limited & $512(38.5)$ \\
\hline Severe & $134(10.1)$ \\
\hline \multicolumn{2}{|l|}{ Tumor-node-metastasis stage } \\
\hline I & $220(16.5)$ \\
\hline II & $334(25.1)$ \\
\hline III & $776(58.3)$ \\
\hline \multicolumn{2}{|l|}{ Adjuvant chemotherapy } \\
\hline No & $513(38.6)$ \\
\hline Yes & $817(6 \mid .4)$ \\
\hline
\end{tabular}

$P=0.019$ ), and preoperative body weight loss (HR: 1.152 , 95\% CI: $1.014-1.310, P=0.030$ ) were independently associated with OS (Figure 1), along with age (HR: $1.441,95 \% \mathrm{CI}$ : 1.068-1.787, $P<0.001$ ), histological grade (HR: $1.382,95 \%$ CI: $1.051-1.748, P=0.014$ ), tumor location (HR: $0.761,95 \%$ CI: $0.687-0.843, P<0.001$ ), and seventh TNM stage (HR: $3.341,95 \%$ CI: $2.755-4.052, P<0.001)$.

In stage-stratified analysis, multivariate analysis revealed that preoperative body weight loss was independently associated with OS in stage III disease (HR: $1.223,95 \%$ CI: 1.065-1.405, $P=0.004$; Figure 2), whereas PNI was only marginally associated (HR: 1.299, 95\% CI: 0.990-1.706,
$P=0.059$; Table S1). However, in stage I and II disease, the prognostic significance was not significant (all $P>0.05$ ). In patients with stage III GC, preoperative body weight loss stratified 5-year OS from $41.1 \%$ to $26.5 \%$. When stratified by adjuvant chemotherapy, the prognostic significance of preoperative body weight loss was maintained in patients treated with surgery plus adjuvant chemotherapy and in patients treated with surgery alone $(P<0.001 ; P=0.003$; Figure 3).

The relationship between the preoperative body weight loss and clinicopathologic characteristics in GC patients is shown in Table 3. Severe preoperative body weight loss was associated with larger tumor size $(P<0.001)$, elevated PNI $(P<0.001)$, elevated performance status $(P<0.001)$, lower BMI $(P<0.001)$, lower serum albumin level $(P<0.001)$, and higher TNM stage $(P<0.001)$. Of note, the prognostic significance of preoperative body weight loss was maintained when stratified by PNI (PNI 0: $P<0.001$; PNI 1: $P=0.003$ ).

\section{Discussion}

Malnutrition is prevalent among surgical patients with gastrointestinal malignancy. ${ }^{21,22}$ However, the association between nutritional status and prognosis in GC patients undergoing curative surgery is unclear. In the present study, we explored the prognostic value of several nutrition-based indices. We found that preoperative body weight loss was an independent prognostic factor for OS, especially in patients with stage III disease, and may have comparable prognostic ability to other established nutrition-based indices.

Accumulating evidence has indicated that cancer and nutritional status are closely linked. ${ }^{23,24}$ However, the underlying reasons why preoperative malnutrition causes a poor outcome remain unclear. Several potential mechanisms have been proposed for the relationship. First, malnutrition impairs immunological functions, resulting in an increased risk of postoperative infectious and metastasis..$^{25}$ Second, malnutrition, as a chronic or subacute state, combines varying degrees of undernutrition and inflammatory activity, which contribute to a change in body composition and diminished function. ${ }^{26,27}$ Third, malnutrition can lead to various postoperative complications, reduced therapeutic efficacy of drugs, and more importantly, the activation of systemic inflammatory response. ${ }^{28}$

Over the last several decades, the value of preoperative nutritional status to predict outcome has attracted increasing attention. One recent prospective study, which used pretreatment BMI to assess nutritional status, showed that nutritional status might be a prognostic factor in older patients with GC. ${ }^{29}$ 
Table 2 Univariate and multivariate analyses of overall survival in I,330 patients undergoing curative resection for gastric cancer

\begin{tabular}{|c|c|c|}
\hline \multirow[t]{2}{*}{ Characteristics } & \multirow{2}{*}{$\frac{\text { Univariate analysis }}{\text { HR }(95 \% \mathrm{CI}) \boldsymbol{P} \text {-value }}$} & \multirow{2}{*}{$\begin{array}{l}\text { Multivariate analysis } \\
\text { HR }(95 \% \mathrm{Cl}) P \text {-value }\end{array}$} \\
\hline & & \\
\hline Age (years) & $<0.001$ & $<0.001$ \\
\hline$<60$ & I & I \\
\hline$\geq 60$ & $1.489(1.254,1.768)$ & I.44I (I.210, I.7I7) \\
\hline Sex & 0.735 & \\
\hline Male & I & \\
\hline Female & I.032 (0.859, I.24I) & \\
\hline Tumor size $(\mathrm{cm})$ & $<0.00 \mathrm{I}$ & 0.847 \\
\hline$<5$ & 1 & I \\
\hline$\geq 5$ & $\mathrm{I} .736(\mathrm{I} .46 \mathrm{I}, 2.062)$ & $0.982(0.819,1.178)$ \\
\hline Tumor location & $<0.001$ & $<0.001$ \\
\hline Upper third & 1 & I \\
\hline Middle/lower third & $0.675(0.612,0.745)$ & $0.76 \mathrm{I}(0.687,0.843)$ \\
\hline Histological grade & 0.012 & 0.014 \\
\hline Well differentiated & I & I \\
\hline Poorly differentiated & $1.379(1.072,1.774)$ & $1.382(1.068,1.787)$ \\
\hline Prognostic nutritional index & $<0.00 \mathrm{I}$ & 0.019 \\
\hline 0 & 1 & I \\
\hline I & $1.627(\mathrm{I} .274,2.078)$ & I.356 (I.05।, I.748) \\
\hline Performance status & 0.187 & \\
\hline 0 & I & \\
\hline $1 / 2$ & $0.894(0.756,1.056)$ & \\
\hline Body mass index $\left(\mathrm{kg} / \mathrm{m}^{2}\right)$ & 0.056 & \\
\hline$<18.5$ & I & \\
\hline$\geq 18.5$ & $0.901(0.809,1.003)$ & \\
\hline Serum albumin (g/L) & $<0.001$ & 0.064 \\
\hline$\geq 35$ & 1 & I \\
\hline$<35$ & $1.704(1.316,2.206)$ & $1.293(0.985,1.697)$ \\
\hline Preoperative body weight loss & $<0.00 \mathrm{I}$ & 0.030 \\
\hline No & I & I \\
\hline Limited/severe & $1.340(1.184,1.517)$ & $1.152(1.014,1.310)$ \\
\hline Tumor-node-metastasis stage & $<0.001$ & $<0.001$ \\
\hline I & I & I \\
\hline$\| / I I I$ & $3.568(2.961,4.299)$ & $3.34 \mathrm{I}(2.755,4.052)$ \\
\hline Adjuvant chemotherapy & 0.388 & \\
\hline No & I & \\
\hline Yes & $0.925(0.776,1.104)$ & \\
\hline
\end{tabular}

Abbreviations: $\mathrm{Cl}$, confidence interval; $\mathrm{HR}$, hazard ratio.

van der Schaaf et al reported that patients with esophageal cancer who experienced severe preoperative body weight loss had decreased 5-year survival after surgery but no increased risk of postoperative complications. ${ }^{11}$ A study by Lien et al revealed that preoperative serum albumin level not only reflected the nutritional condition but also predicted the longterm outcome in patients with GC. ${ }^{30}$ In addition, the impact of the PNI on prognosis in GC remains unclear, especially in stage-stratified analysis. ${ }^{15,16}$ However, in our study, multivariate analysis revealed that the preoperative body weight loss was a predictor of OS, especially in patients with stage III GC. Obviously, in the context of curative resectable GC, the preoperative body weight loss might exert more potent prognostic value than other nutrition-based indices, including the PNI, performance status, BMI, and serum albumin. Furthermore, our conclusions are supported by other studies. One group found that body weight loss, both before and during radiotherapy, were valuable prognostic indicators for 5-year disease-specific survival in patients with head and neck cancer. ${ }^{31}$ Another study reported that critical body weight loss had independent prognostic impact on long-term survival in patients with nasopharyngeal carcinoma. ${ }^{32}$ Until now, few studies explored the relationship between preoperative body weight loss and survival in patients with GC. 

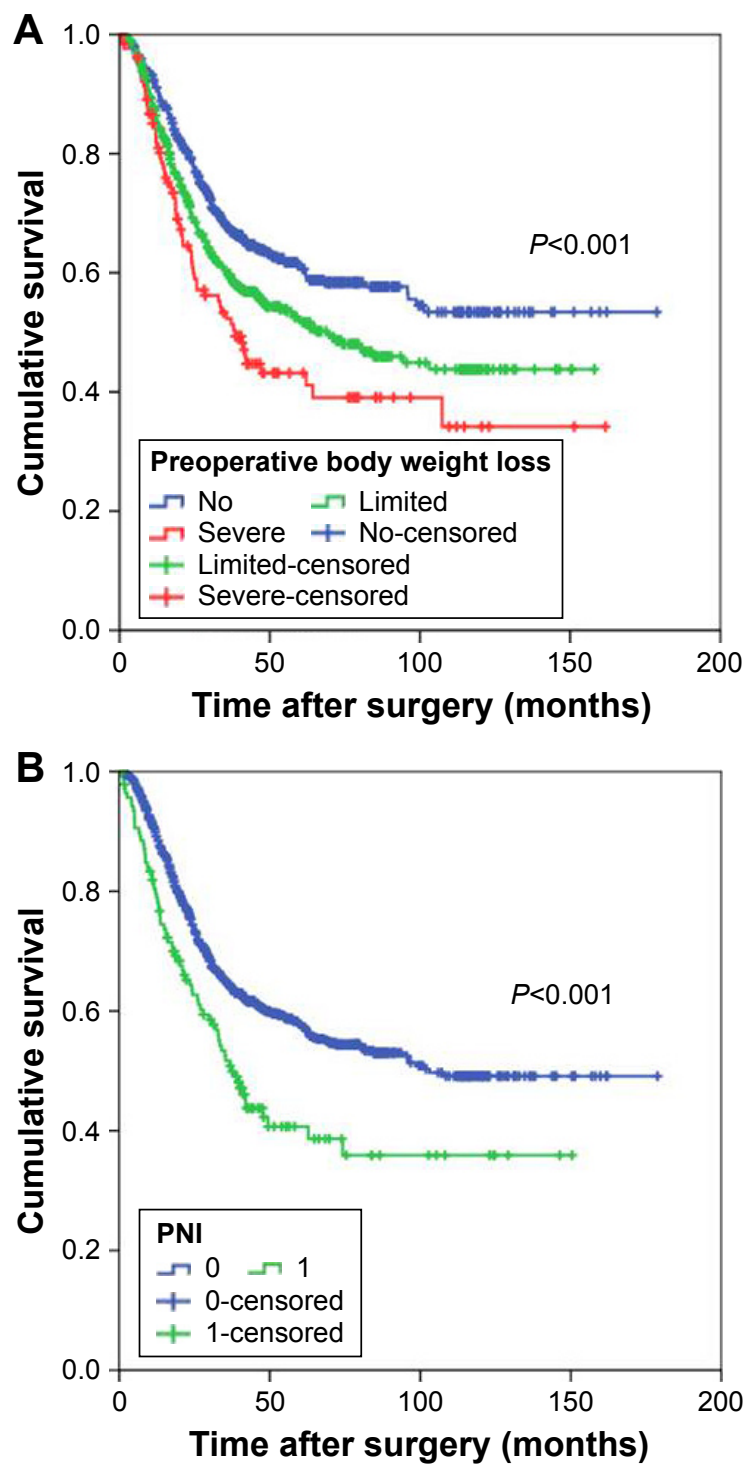

Figure I Overall survival of patients with gastric cancer based on the preoperative body weight loss (A) and PNI (B).

Abbreviation: PNI, prognostic nutritional index.

Our study may add to the evidence that preoperative body weight loss is a valuable prognostic factor for GC. Patients with severe preoperative body weight loss usually have a poorer quality of life, a decreased response to adjuvant treatment, and an increased risk of chemotherapy-induced toxicity. We speculated that all these individual factors might lead to a poor clinical outcome. In addition, whether a targeted preoperative nutritional intervention can improve outcomes in these patients is worth further study. ${ }^{33}$

In our study, we found that severe preoperative body weight loss was associated with larger tumor size and higher TNM stage. The observation was consistent with previous studies that indicated that poor nutritional status was significantly

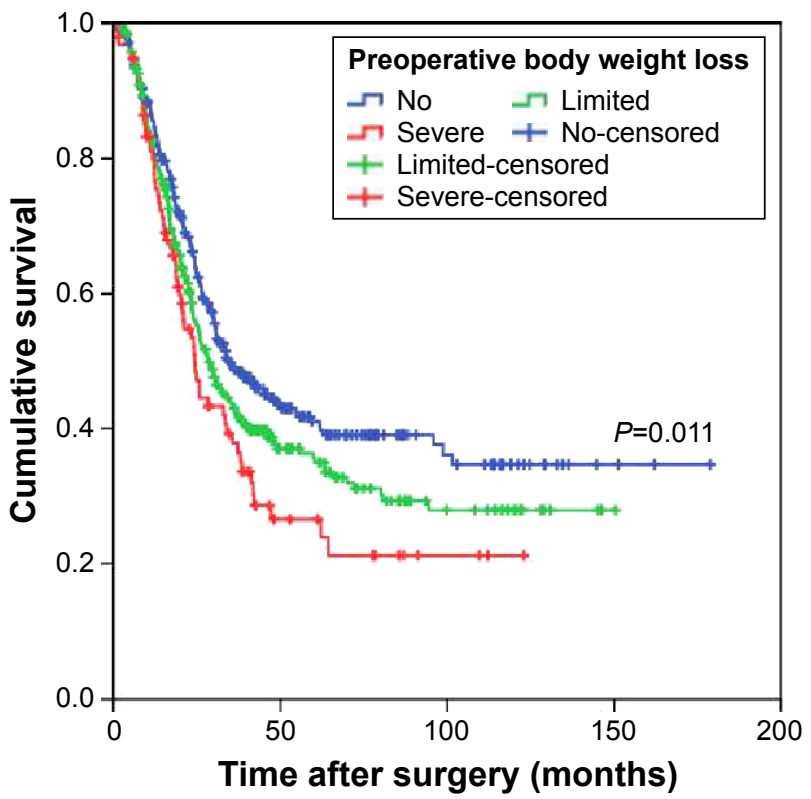

Figure 2 Overall survival based on the preoperative body weight loss in patients with stage III gastric cancer.

parallel to tumor progression and more aggressive tumor behavior. ${ }^{34} \mathrm{Of}$ note, many studies have revealed that preoperative body weight loss is also affected by tumor location. Taste changes and food aversion, which result in discomfort and difficulties with eating, usually play an important role in body weight loss. ${ }^{35}$ In fact, we also hypothesize that there might be a relationship between tumor location and early satiety, leading to more body weight loss than an alternative tumor location. However, we did not find an association between severe preoperative body weight loss and tumor location, and prospective multicenter clinical studies are warranted as validation studies. In addition, the prognostic significance of preoperative body weight loss was still maintained when stratified by adjuvant chemotherapy. Dewys et al also reported that body weight loss was associated with a significantly decreased survival in patients receiving chemotherapy for various cancers. ${ }^{36}$ As shown in Figure 3, patients with severe preoperative body weight loss treated with surgery alone seem to have better OS than those treated with surgery plus adjuvant chemotherapy. Although we did not carry out a statistical analysis because of the limited number of cases, we speculated that patients with severe preoperative body weight loss might not benefit from adjuvant chemotherapy. Furthermore, whether preoperative body weight loss could aid in the selection of GC patients likely to benefit from adjuvant chemotherapy would be of considerable interest. Future studies, especially prospective randomized controlled studies, are needed. 

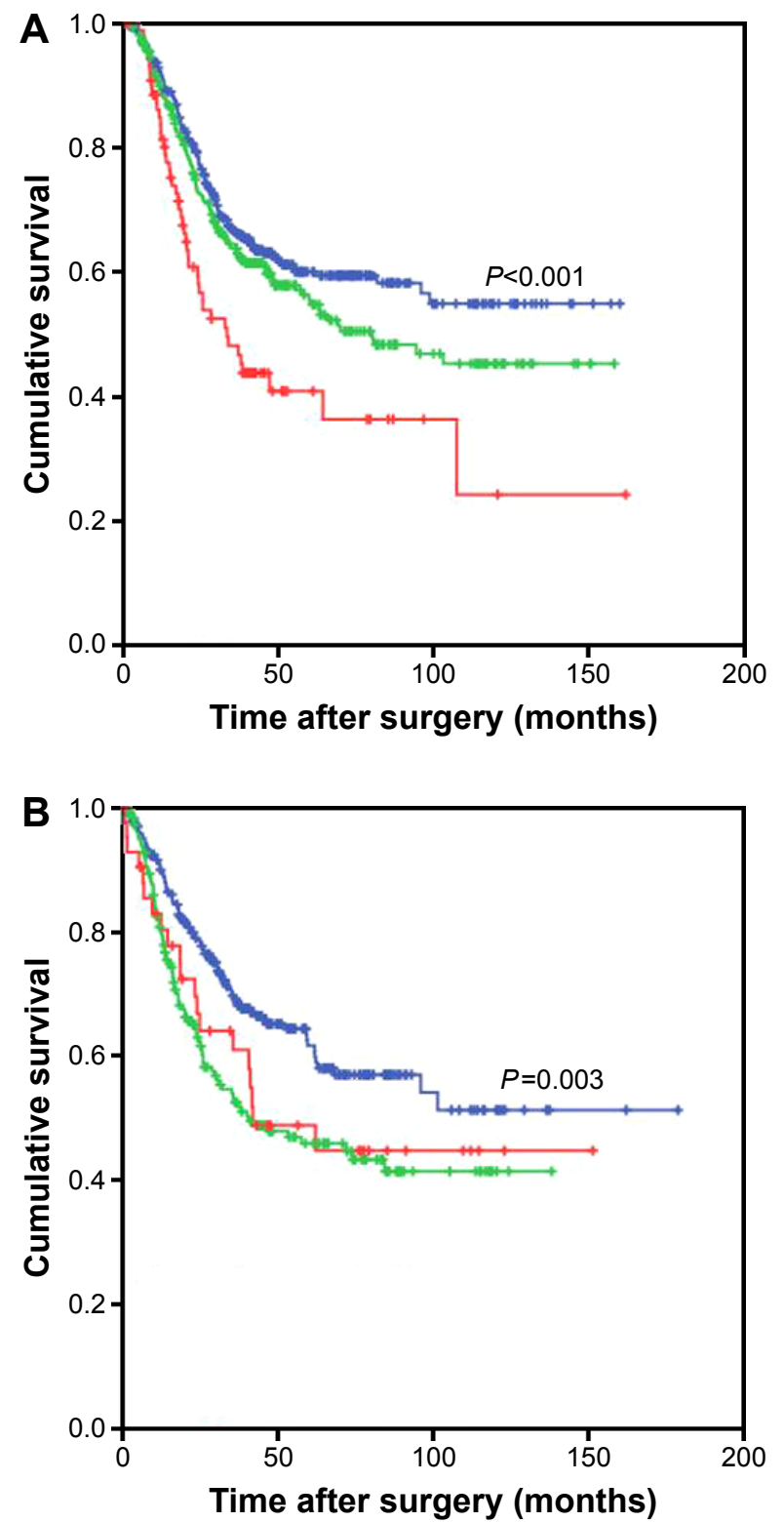

$$
\begin{aligned}
& \text { Preoperative body weight loss } \\
& \neg \text { No } \neg \text { Limited } \neg \text { Severe }+ \text { No-censored } \\
& + \text { Limited-censored }+ \text { Severe-censored }
\end{aligned}
$$

Figure 3 Overall survival based on the preoperative body weight loss in patients with gastric cancer (A) treated with surgery and adjuvant chemotherapy and (B) treated with surgery alone.

In clinical practice, patients with severe preoperative body weight loss may need less aggressive adjuvant treatment, or should perhaps forego it. Furthermore, these patients may need closer follow-up and early intervention based on objective tests. Finally, patients with severe preoperative body weight loss may benefit from early nutritional support. Despite promising results from nutritional intervention, no large-scale prospective studies have investigated the role of early nutrition support in these patients.

\begin{tabular}{|c|c|c|c|c|}
\hline Characteristics & $\begin{array}{l}\text { No } \\
(n=684)\end{array}$ & $\begin{array}{l}\text { Limited } \\
(n=5 \mid 2)\end{array}$ & $\begin{array}{l}\text { Severe } \\
(n=134)\end{array}$ & $P$-value \\
\hline \multicolumn{5}{|l|}{ Age (years) } \\
\hline$<60$ & 366 & 269 & 69 & 0.889 \\
\hline$\geq 60$ & 318 & 243 & 65 & \\
\hline \multicolumn{5}{|l|}{ Sex } \\
\hline Male & 216 & 164 & 45 & 0.901 \\
\hline Female & 468 & 348 & 89 & \\
\hline \multicolumn{5}{|l|}{ Tumor size $(\mathrm{cm})$} \\
\hline$<5$ & 429 & 252 & 57 & $<0.001$ \\
\hline$\geq 5$ & 255 & 260 & 77 & \\
\hline \multicolumn{5}{|l|}{ Tumor location } \\
\hline Upper third & 250 & 211 & 50 & 0.161 \\
\hline Middle third & 137 & 115 & 26 & \\
\hline Lower third & 297 & 186 & 58 & \\
\hline \multicolumn{5}{|l|}{ Histological grade } \\
\hline Well differentiated & 127 & 79 & 19 & $0.24 I$ \\
\hline Poorly differentiated & 557 & 433 & 115 & \\
\hline \multicolumn{5}{|c|}{ Prognostic nutritional index } \\
\hline 0 & 626 & 457 & 104 & $<0.001$ \\
\hline I & 58 & 55 & 30 & \\
\hline \multicolumn{5}{|l|}{ Performance status } \\
\hline 0 & 236 & 105 & 23 & $<0.001$ \\
\hline I & 426 & 380 & 104 & \\
\hline 2 & 22 & 27 & 7 & \\
\hline \multicolumn{5}{|l|}{ Body mass index $\left(\mathrm{kg} / \mathrm{m}^{2}\right)$} \\
\hline$<18.5$ & 239 & 229 & 82 & $<0.001$ \\
\hline$\geq 18.5$ to $<25.0$ & 228 & 176 & 39 & \\
\hline$\geq 25.0$ & 217 & 107 & 13 & \\
\hline \multicolumn{5}{|l|}{ Serum albumin $(g / L)$} \\
\hline$\geq 35$ & 638 & 462 & 107 & $<0.001$ \\
\hline$<35$ & 46 & 50 & 27 & \\
\hline \multicolumn{5}{|c|}{ Tumor-node-metastasis stage } \\
\hline I & 158 & 54 & 8 & $<0.001$ \\
\hline II & 174 & 136 & 24 & \\
\hline III & 352 & 322 & 102 & \\
\hline \multicolumn{5}{|l|}{ Adjuvant chemotherapy } \\
\hline No & 278 & 190 & 45 & 0.211 \\
\hline Yes & 406 & 322 & 89 & \\
\hline
\end{tabular}

Table 3 Correlation of preoperative body weight loss with clinicopathologic characteristics

\section{Limitations}

Our study has several limitations. First, it was a retrospective single-center study. However, surgical procedures, laboratory assays, and patient follow-up were standardized and uniform during the entire study period. Second, we lacked the postoperative nutritional status, which might have confounded the results. Nevertheless, our large sample size provided a valid base to assess the prognostic value of nutrition-based indices.

\section{Conclusion}

Preoperative body weight loss is independently associated with OS in patients with GC, especially in stage III disease. Preoperative body weight loss may have better clinical 
prognostic value than other established nutrition-based indices for identifying high-risk patients with GC.

\section{Acknowledgments}

The authors wish to thank all the people who helped with this study.

\section{Author contributions}

All authors contributed toward data analysis, drafting and revising the paper and agree to be accountable for all aspects of the work.

\section{Disclosure}

The authors report no conflicts of interest in this work.

\section{References}

1. Kamangar F, Dores GM, Anderson WF. Patterns of cancer incidence, mortality, and prevalence across five continents: defining priorities to reduce cancer disparities in different geographic regions of the world. $J$ Clin Oncol. 2006;24(14):2137-2150.

2. Jemal A, Bray F, Center MM, Ferlay J, Ward E, Forman D. Global cancer statistics. CA Cancer J Clin. 2011;61(2):69-90.

3. Chen W, Zheng R, Zeng H, Zhang S. The incidence and mortality of major cancers in China, 2012. Chin J Cancer. 2016;35(1):73.

4. Sasako M, Sano T, Yamamoto S, et al. D2 lymphadenectomy alone or with para-aortic nodal dissection for gastric cancer. $N$ Engl J Med. 2008;359(5):453-462.

5. Yan L. The journey of personalizing gastric cancer treatment. Chin $J$ Cancer. 2016;35(1):84.

6. Roukos DH, Kappas AM. Perspectives in the treatment of gastric cancer. Nat Clin Pract Oncol. 2005;2(2):98-107.

7. Garth AK, Newsome CM, Simmance N, Crowe TC. Nutritional status, nutrition practices and post-operative complications in patients with gastrointestinal cancer. J Hum Nutr Diet. 2010;23(4):393-401.

8. Ma L, Luo GY, Ren YF, et al. Concurrent chemoradiotherapy combined with enteral nutrition support: a radical treatment strategy for esophageal squamous cell carcinoma patients with malignant fistulae. Chin $J$ Cancer. 2017;36(1):8.

9. Zhang SS, Yang H, Luo KJ, et al. The impact of body mass index on complication and survival in resected oesophageal cancer: a clinical-based cohort and meta-analysis. Br J Cancer. 2013;109(11):2894-2903.

10. Fiala $\mathrm{O}$, Pesek M, Finek J, et al. Serum albumin is a strong predictor of survival in patients with advanced-stage non-small cell lung cancer treated with erlotinib. Neoplasma. 2016;63(3):471-476.

11. van der Schaaf MK, Tilanus HW, van Lanschot JJ, et al. The influence of preoperative weight loss on the postoperative course after esophageal cancer resection. J Thorac Cardiovasc Surg. 2014;147(1): 490-495.

12. Jiang N, Deng JY, Ding XW, et al. Prognostic nutritional index predicts postoperative complications and long-term outcomes of gastric cancer. World J Gastroenterol. 2014;20(30):10537-10544.

13. Chen HN, Chen XZ, Zhang WH, et al. The impact of body mass index on the surgical outcomes of patients with gastric cancer: a 10-year, single-institution cohort study. Medicine (Baltimore). 2015;94(42): e1769.

14. Hinata N, Miyake H, Miyazaki A, Nishikawa M, Tei H, Fujisawa M. Performance status as a significant prognostic predictor in patients with urothelial carcinoma of the bladder who underwent radical cystectomy. Int J Urol. 2015;22(8):742-746.

15. Sakurai K, Ohira M, Tamura T, et al. Predictive potential of preoperative nutritional status in long-term outcome projections for patients with gastric cancer. Ann Surg Oncol. 2016;23(2):525-533.
16. Migita K, Takayama T, Saeki K, et al. The prognostic nutritional index predicts long-term outcomes of gastric cancer patients independent of tumor stage. Ann Surg Oncol. 2013;20(8):2647-2654.

17. Japanese Gastric Cancer Association. Japanese classification of gastric carcinoma - 2nd english edition. Gastric Cancer. 1998;1(1):10-24.

18. Washington K. 7th edition of the AJCC cancer staging manual: stomach. Ann Surg Oncol. 2010;17(12):3077-3079.

19. Paoletti X, Oba K, Burzykowski T, et al. Benefit of adjuvant chemotherapy for resectable gastric cancer: a meta-analysis. JAMA. 2010;303(17): $1729-1737$.

20. Nozoe T, Ninomiya M, Maeda T, Matsukuma A, Nakashima H, Ezaki T. Prognostic nutritional index: a tool to predict the biological aggressiveness of gastric carcinoma. Surg Today. 2010;40(5):440-443.

21. Hennessey DB, Burke JP, Ni-Dhonochu T, Shields C, Winter DC, Mealy K. Preoperative hypoalbuminemia is an independent risk factor for the development of surgical site infection following gastrointestinal surgery: a multi-institutional study. Ann Surg. 2010;252(2):325-329.

22. Schiesser M, Muller S, Kirchhoff P, Breitenstein S, Schafer M, Clavien PA. Assessment of a novel screening score for nutritional risk in predicting complications in gastro-intestinal surgery. Clin Nutr. 2008; 27(4):565-570.

23. Capozzi LC, McNeely ML, Lau HY, et al. Patient-reported outcomes, body composition, and nutrition status in patients with head and neck cancer: results from an exploratory randomized controlled exercise trial. Cancer. 2016;122(8):1185-1200.

24. Arrieta O, De la Torre-Vallejo M, Lopez-Macias D, et al. Nutritional status, body surface, and low lean body mass/body mass index are related to dose reduction and severe gastrointestinal toxicity induced by afatinib in patients with non-small cell lung cancer. Oncologist. 2015;20(8):967-974.

25. Xu J, Zhong Y, Jing D, Wu Z. Preoperative enteral immunonutrition improves postoperative outcome in patients with gastrointestinal cancer. World J Surg. 2006;30(7):1284-1289.

26. Soeters PB, Reijven PL, van Bokhorst-de van der Schueren MA, et al A rational approach to nutritional assessment. Clin Nutr. 2008;27(5): 706-716.

27. Van Cutsem E, Arends J. The causes and consequences of cancerassociated malnutrition. Eur J Oncol Nurs. 2005;9(Suppl 2):S51-S63.

28. Sun KY, Xu JB, Chen SL, et al. Novel immunological and nutritionalbased prognostic index for gastric cancer. World J Gastroenterol. 2015; 21(19):5961-5971.

29. Minami Y, Kawai M, Fujiya T, et al. Family history, body mass index and survival in Japanese patients with stomach cancer: a prospective study. Int J Cancer. 2015;136(2):411-424.

30. Lien YC, Hsieh CC, Wu YC, et al. Preoperative serum albumin level is a prognostic indicator for adenocarcinoma of the gastric cardia. J Gastrointest Surg. 2004;8(8):1041-1048.

31. Langius JA, Bakker S, Rietveld DH, et al. Critical weight loss is a major prognostic indicator for disease-specific survival in patients with head and neck cancer receiving radiotherapy. Br J Cancer. 2013;109(5): 1093-1099.

32. Zeng Q, Shen LJ, Guo X, Guo XM, Qian CN, Wu PH. Critical weight loss predicts poor prognosis in nasopharyngeal carcinoma. BMC Cancer. 2016;16(1):169.

33. Weimann A, Braga M, Harsanyi L, et al. ESPEN Guidelines on Enteral Nutrition: surgery including organ transplantation. Clin Nutr. 2006;25(2): 224-244.

34. Crumley AB, Stuart RC, McKernan M, McMillan DC. Is hypoalbuminemia an independent prognostic factor in patients with gastric cancer? World J Surg. 2010;34(10):2393-2398.

35. Argiles JM. Cancer-associated malnutrition. Eur J Oncol Nurs. 2005; 9(Suppl 2):S39-S50.

36. Dewys WD, Begg C, Lavin PT, et al. Prognostic effect of weight loss prior to chemotherapy in cancer patients. Eastern Cooperative Oncology Group. Am J Med. 1980;69(4):491-497. 


\section{Supplementary material}

Table SI Univariate and multivariate analyses of overall survival in 776 stage III patients undergoing curative resection for gastric cancer

\begin{tabular}{|c|c|c|}
\hline \multirow[t]{2}{*}{ Characteristics } & \multirow{2}{*}{$\frac{\text { Univariate analysis }}{\text { HR }(95 \% \mathrm{Cl}) P \text {-value }}$} & \multirow{2}{*}{$\begin{array}{l}\text { Multivariate analysis } \\
\text { HR }(95 \% \mathrm{CI}) P \text {-value }\end{array}$} \\
\hline & & \\
\hline Age (years) & $<0.00 \mathrm{I}$ & 0.009 \\
\hline$<60$ & I & I \\
\hline$\geq 60$ & $1.459(1.210,1.759)$ & $1.290(1.065,1.564)$ \\
\hline Sex & 0.668 & \\
\hline Male & 1 & \\
\hline Female & $1.045(0.856,1.275)$ & \\
\hline Tumor size $(\mathrm{cm})$ & 0.083 & \\
\hline$<5$ & $\mathrm{I}$ & \\
\hline$\geq 5$ & I.I83 $(0.978,1.43$ I) & \\
\hline Tumor location & $<0.00$ I & $<0.001$ \\
\hline Upper third & 1 & 1 \\
\hline Middle/lower third & $0.785(0.705,0.874)$ & $0.805(0.720,0.900)$ \\
\hline Histological grade & 0.106 & \\
\hline Well differentiated & I & \\
\hline Poorly differentiated & $1.272(0.950,1.704)$ & \\
\hline Prognostic nutritional index & 0.005 & 0.059 \\
\hline 0 & 1 & I \\
\hline 1 & $1.455(1.118,1.894)$ & $1.299(0.990,1.706)$ \\
\hline Performance status & 0.049 & 0.087 \\
\hline 0 & 1 & I \\
\hline $\mathrm{I} / 2$ & $0.826(0.684,0.999)$ & $0.843(0.693,1.025)$ \\
\hline Body mass index $\left(\mathrm{kg} / \mathrm{m}^{2}\right)$ & 0.035 & 0.101 \\
\hline$<18.5$ & 1 & I \\
\hline$\geq 18.5$ & $0.880(0.782,0.991)$ & $0.903(0.800,1.020)$ \\
\hline Serum albumin $(g / L)$ & 0.008 & 0.137 \\
\hline$\geq 35$ & 1 & 1 \\
\hline$<35$ & $1.450(1.100,1.911)$ & $1.246(0.933,1.663)$ \\
\hline Preoperative body weight loss & 0.003 & 0.004 \\
\hline No & 1 & I \\
\hline Limited/severe & $1.227(1.073,1.403)$ & $1.223(1.065,1.405)$ \\
\hline Depth of tumor & $<0.001$ & 0.002 \\
\hline $\mathrm{TI} / \mathrm{T} 2$ & I & I \\
\hline $\mathrm{T} 3 / \mathrm{T} 4$ & $1.540(1.318,1.800)$ & $1.375(1.123,1.684)$ \\
\hline Levels of lymph node & $<0.00 \mathrm{I}$ & $<0.001$ \\
\hline No/NI & I & I \\
\hline $\mathrm{N} 2 / \mathrm{N} 3$ & 1.758 (I.53।, 2.019) & $1.542(1.349,1.763)$ \\
\hline Adjuvant chemotherapy & 0.005 & 0.113 \\
\hline No & 1 & I \\
\hline Yes & $0.753(0.618,0.916)$ & $0.849(0.694,1.040)$ \\
\hline
\end{tabular}

Abbreviations: $\mathrm{Cl}$, confidence interval; $\mathrm{HR}$, hazard ratio.

\section{Publish your work in this journal}

OncoTargets and Therapy is an international, peer-reviewed, open access journal focusing on the pathological basis of all cancers, potential targets for therapy and treatment protocols employed to improve the management of cancer patients. The journal also focuses on the impact of management programs and new therapeutic agents and protocols on patient perspectives such as quality of life, adherence and satisfaction. The manuscript management system is completely online and includes a very quick and fair peer-review system, which is all easy to use. Visit http://www.dovepress.com/testimonials.php to read real quotes from published authors. 